Paper presented at Australian Academy of Science Symposium on Natural Hazards in Australia, Section 3: Community and Individual Responses to Natural Hazards, May 26-29, 1976, Canberra, Australia.

\title{
CONSEQUENCES OF EARTHQUAKE PREDICTION ON OTHER ADJUSTMENTS TO EARTHQUAKES
}

\author{
J. E. Haas* and D. S. Mileti**
}

\section{ABSTRACT}

Earthquake prediction is a new technology soon to be added to the other adjustments which can be used by a community to cope with the earthquake hazard. Governmental and business organisations will be faced with new challenges when a specific earthquake prediction is issued for their area. Research on organisational response to such a prediction indicates that there will be significant positive and negative consequences. With an extended lead time of several years the risk of death and injury can be brought to near zero but the resulting local economic recession will be of major proportions.

When scientifically based earthquake predictions become available in the near future, communities will have one more weapon in the arsenal being used (or at least available for use) to minimize the losses and disruption which damaging earthquakes produce (White and Haas; Ayre (I)). Where does this potential new coping mechanism or adjustment fit into the picture? What will be the impact of earthquake prediction on the use of and priority given to other earthquake hazard mitigation measures? Will this new product of the scientific enterprise increase or decrease social risk generally?

In this paper we first examine the set of adjustments currently available for use in coping with the earthquake threat. We then describe the characteristics of the early earthquake predictions and outline what current research findings indicate will be the short-term consequences of a specific earthquake prediction for a city. Finally, we estimate how the availability of earthquake prediction will alter the set of adjustments which a city makes to the earthquake hazard.

Communities located in seismic risk areas may cope with the fact through the use of one or more of the following adjustments:

1. Land use control.

If land areas are documented as being subject to liquefaction, landslide or especially high in risk for any other reason, legal restrictions on the use of the land may be instituted (Baker and McPhee (2)).

2. Seismic resistant construction.

Architects and engineers may insist that their client's buildings be designed and constructed to resist certain levels of shaking. More commonly the local political jurisdiction adopts a version of the Uniform Building code which the decision makers

* Institute of Behavioral Science, University of Colorado, Boulder, CO 80302, U.S.A.

* * Department of Sociology, Colorado State University, Fort Collins, CO 80521, U.S.A. believe provides, within the constraints of economic feasibility, for the safety of the citizens from the earthquake threat. Facilities such as underground utilities, bridges, overpasses, hospitals and schools may be designed to withstand all but the most severe shaking so that functions critical to the survival of the community will not be interrupted (Ayre (2)).

3. Prevention of secondary impacts.

Special precautions are often taken in an effort to insure that fire and hazardous materials do not become significant secondary impacts following an earthquake (Ayre (1)).

4. Preparedness for emergency response.

Communities may have elaborate contingency plans including the planned use of specialized personnel and equipment to respond quickly to the host of urgent demands, e.g. search and rescue of trapped victims, which may arise soon after an earthquake disaster. Individual organisations may also have disaster response plans. Normally these plans are forgotten soon after being completed (Mileti, Drabek and Haas (7)).

5. Relief and rehabilitation efforts.

A variety of efforts, often with outside assistance, come into operation following the earthquake disaster. These efforts are intended to provide a range of services and information which will help in the recovery of individuals, families and businesses. There are also programmes designed to assist governmental agencies and the financial solvency of the city or county as a whole (Mileti (6)).

\section{Insurance.}

One method of handling earthquake losses is through insurance. Though it is seldom used, insurance carriers do offer earthquake coverage but at a price often considered exorbitant. Some large firms develop selfinsurance programs (White and Haas (9)).

Any one or a combination of these 
adjustments may be in use within a given community. Because of the infrequency of damaging earthquakes in any area, few, if any, communities utilize all six of the adjustments to the maximum. Indeed, it is rare that any one of the adjustments is fully developed and implemented within a city. It is the classic case of underutilization of available prevention and mitigation measures.

Enter earthquake prediction. Let us assume the following sequence of events.* In July, 1976, the United States Geological Survey (USGS) announced that an area including most of the greater Los Angeles basin was being designated as an area of intensive study of possible earthquake precursor data. The USGS would give timely notice should the data show sufficient probability of an earthquake occurrence. The agency made it clear that it was not announcing an official earthquake prediction. Two reputable nongovernment seismologists said that their interpretation of the available data convinced them that there was a $25 \%$ probability of a damaging earthquake along a large section of a well-known local fault in 1979. In early August, 1977, the USGS released the first official prediction of an earthquake. There was a $50 \%$ probability of an earthquake of magnitude 7.0 or greater to strike a designated area in september or October, 1979.

In mid-November, 1978, some nine months prior to the expected earthquake, the prediction was revised to an $80 \%$ probability that the earthquake would occur in the month of September, 1979, with a Richter magnitude of 7.1-7.4. Finaliy, sixty days before the expected event, the USGS further revised the prediction. The earthquake would occur during the first week of september, 1979, with an expected magnitude of 7.3. The probability was said to still be $80 \%$.

Given that scenario of earthquake prediction information, what are likely to be the consequences for the "target" community? The consequences, whatever they may be, will flow from and be reflected in the actions of involved organisations.

\section{ORGANISATIONAL RESPONSE TO THE PREDICTION INFORMATION}

Every organisation whether public or private has its own domain to protect and enhance if possible (Haas and Drabek). Further, there are other groups, organisations and publics which are highly salient for the organisation's survival and success.

Any organisation having a significant involvement in the community or area to which the earthquake prediction applies will for the first time be faced with information about likely environmental changes. First, the prediction indicates probable physical changes and consequent social and economic

\footnotetext{
* These brief excerpts from a scenario reflect tentative findings from our research on the "Socioeconomic and Political Consequences of Earthquake Prediction" (NSF Grant \#AEN 74-24079). The opinions expressed herein do not necessarily represent those of the National Science Foundation.
}

disruption from an earthquake per se. secondly, the prediction itself may produce changes in the environment of the organisation.

How shall we conceptualize the possible adjustments and response of public and private organisations to this new type of information, the prediction of a specific time, locale and magnitude of an earthquake? Our analysis to date suggests that there are nine analytical categories which encompass the full range of possible organisational responses. See Figure 1 for examples. The actions of any organisation whether a public agency or a business corporation will fall into one or more of the nine cells in the matrix.

It is also conceivable that a few organisations may do nothing, at least for a time. Interestingly, we have learned that for many organisations the views of their top executives regarding the credibility of the prediction are not a significant matter. If segments of the public and/or certain other organisations respond as though they believe the earthquake prediction, thus changing the environment, then that change must be taken into account regardless of the executive's personal beliefs.

Using the abstract categories reflected in Figure I, we developed a series of questions designed to tap the probable response of any organisation to a specific earthquake prediction such as the one described in the previous section of this paper.** Selected questions are presented below.

1. Would your organisation make a serious attempt to determine the credibility of the earthquake prediction?

2. Would there be a significant attempt by your organisation to assess the likely consequences of the earthquake prediction itself on your organisation.

3. In this assessment, would your organisation extensively use information acquired from other organizations?

4. Would your organisation assess the vulnerability of your buildings, equipment, and inventory as a result of the earthquake prediction?

5. Would your organisation assess the vulnerability of its financial resources as a result of the earthquake prediction?

6. Would your organisation gather information with which to consider what new responsibilities it may have as a result of the earthquake prediction?

7. Would your organisation alter task assignments for a significant proportion of its current staff?

8. Would any area of your organisation's responsibility be changed by a directive from another organisation, e.g. local, state, or Federal government, or some other level in the system of which your organisation is a part?

** A description of the unique methodology used in this research effort may be seen in D. S. Mileti and J. E. Haas, "A Methodology for Future Collective Events: The Case of Earthquake Prediction Response", paper presented at the 1976 annual meeting of the Midwest Sociological Society, St. Louis, April 23, 1976. 
9. Would the earthquake prediction create new opportunities for your organisation, e.g. increased responsibility, income, growth, or less governmental regulation?

10. Would there be a significant increase in the amount of interaction your organisation has with state or Federal legislatures?

11. Would your organisation actively attempt to inform or educate the public or clients as a result of the earthquake prediction?

12. Would your organisation actively call into question the credibility of the prediction?

13. Would your organisation establish arrangements with other organisations for the use of personnel, supplies, equipment and facilities as a result of the earthquake prediction?

14. Would your organisation plan to curtail activities in the area at risk during the period for which the earthquake is predicted?

15. Would your organisation locate new or additional operations in the area at risk?

16. Would your organisation temporarily relocate its current operations out of the area at risk?

17. Would your organisation permanently relocate its current operations out of the area at risk.

18. Would your organisation rearrange financial priorities in response to the prediction?

19. Would there be a net increase or decrease in the inventory of your organisation as a result of the earthquake prediction?

20. Would your organisation move records to an area not at risk?

21. Would your organisation increase or decrease staff size (including volunteers) prior to the predicted earthquake?

22. Would your organisation provide the opportunity for employees to be reassigned out of the area at risk?

23. What organisation or other level of your own organisation, if any, will have most influence on what your organisation decides to do because of the earthquake prediction?

24. Would your organisation spend a substantial sum of money (more than $\frac{1}{2}$ of $1 \%$ of annual profits) in response to the earthquake prediction, e.g., doing damage assessments, securing facilities, hiring specialists, moving equipment, records or inventories, helping employees relocate?

Notice that most of the questions would apply equally well to other circumstances where information became available about potential and significant environmental changes. Thus, it should be possible to apply the basic conceptual framework to a wide range of organisation-environment settings.

It is too early in the research effort to describe in detail and depth the findings regarding likely organisational responses to an early earthquake prediction, but the broad outlines can be sketched now. Since the responses vary over time, they will be separated into four time phases to coincide with the release of earthquake prediction information at different points in time as described in the above scenario.
Time Phase I (July, 1976-August, 1977)

Information about the "intensive study" by the U.S. Geological Survey is released. Two reputable seismologists predict a damaging earthquake in 3 years (25\% probable).

1. Newspapers immediately reported that "intensive study" meant scientists would be placing more instruments in the area to better measure what was happening in the earth.

2. County and city officials assured the public that there was little cause for worry. Reports in the newspapers. however, made it clear that there was concern for the situation--there were increasing contacts between local and state officials responsible for public works and construction about what state agencies would do if the situation became more serious.

3. Newspapers began series on earthquake prediction telling that several successful predictions had occured before; in China many lives had been saved by the prediction of a large earthquake, and in the USA some small earthquakes had been predicted. However, it was noted that some predictions had been wrong. The newspapers also quoted economic experts as saying that an official earthquake prediction would hurt the economy of the city.

4. By early summer of 1977, eleven months later, it was reported that population growth in the area had slowed. Fewer new businesses had opened, and most construction had stopped.

Time Phase II (August, 1977-November, 1978)

An official prediction by the U.S. Geological Survey is announced in August, 1977; to occur in September or October of 1979; will be 7.0 or greater (Richter magnitude scale); estimated probability is $50 \%$.

1. Immediately after the official prediction, the Governor announced that his Advisory Panel on Earthquake Prediction had examined the Federal government data, and agreed with the prediction. The Governor directed state agencies to prepare for the possible earthquake. Federal agencies were doing the same.

2. Although some local government officials doubted the prediction, nearly all said that appropriate actions would be taken by the city and county departments involved.

3. Within a few days of the prediction, news reports showed that the majority of scientists found the prediction believable. A few scientists said, however, that predictions were not yet possible.

4. Shortly after the prediction, the state Insurance commissioner announced that new earthquake insurance policies would no longer be sold to people living in the area, although people who already had earthquake insurance could keep it. Insurance companies and mortgage lenders began to call upon the government to provide new earthquake insurance programmes to help prevent property 
values from dropping.

5. By September, most newspapers had published maps of the area which showed where the damage would be.

6. Engineering firms in California began to advertise that they would inspect buildings and make recommendations for making them safer. Some business firms began to hire engineers to examine their buildings, and government agencies began to inspect public buildings and dams for safety in case the earthquake occurred. Some government agencies prepared pamphlets on safety measures citizens should take.

7. Planning for construction within 25 miles of the predicted center of the earthquake stopped immediately. Construction work already in progress was continued.

Because of the slow-down in construction, unemployment in the building trades had reached $80 \%$ by December of 1977; people who worked in these trades were looking for work elsewhere.

8. Savings and loan associations operating in the area were forced to reduce, by as much as $80 \%$, the loans they could make in the area, and mortgages were less available. Since new loans required higher down payments, fewer people could get loans and property became difficult to sell.

9. By March of 1978 , seven months after the "official prediction", there was a slight decrease in the money collected from sales taxes. It began to look like some services provided by the government would need to be cut. Longterm planning for the city was drastically revised.

10. In August, 1978, the U.S. Congress began to consider a Federal insurance plan for the predicted earthquake area, because of the economic problems there.

Time Phase III (Mid-November, 1978-late June, 1979)

In November ( $9 \frac{1}{2}$ months prior to the expected earthquake), the U.S. Geological Survey makes the prediction more specific. The earthquake will occur in September, 1979; magnitude will be between 7.1 and 7.4 Richter; the probability is now $80 \%$.

1. On the heels of the revised prediction, media reports showed that most local officials found the prediction believable, and that they were calling for action in preparation for the earthquake from appropriate agencies on all governmental levels. After learning that the state would have inadequate funds, the Governor announced that California was seeking a Presidential Emergency Declaration to provide money for special preparedness measures, and to cope with the severe economic problems in the threatened area. Many employers, both public and private, began to urge their employees to plan their vacation period to coincide with the expected earthquake.

2. Local and state governments speeded up their planning for response before and after the predicted earthquake. Public information drives to familiarise citizens with safety measures were intensified.

3. Measures were taken to reduce the danger from dams and fuel lines that might break in the event of the earthquake. After inspection by state experts, there were plans to partially empty unsafe reservoirs by mid-August, 1979.

4. In early summer, 1979, work was begun to move some governmental offices and equipment out of the area temporarily. Some businesses began to move vital records and sensitive equipment; other businesses began to institute measures to protect their stock. Some large industries announced plans to close down during the time of the predicted earthquake to protect employees. Schools also announced that their opening in the fall would be delayed. A few national business firms in the area moved their facilities and operations to other locations. Because of increasing economic pressures, many small businesses in the area closed their doors. By the end of 1978, 25\% of them had either declared bankruptcy or sold out.

5. Due to decreased business activity, many financial firms and larger retail firms were forced to lay off employees. This was a blow to the local economy. Local businesses and Chamber of Commerce officials began campaigns to assure the public that, in spite of some economic problems, the area and its businesses were basically safe and sound.

6. By June of 1979, it was apparent that the income to local government from taxes had declined.

7. City and county departments concerned with vital services, such as police, sheriff, fire and water departments, requested extra money in order to get ready for the earthquake. The increases could not be granted, but sufficient money for vital services was obtained by cutting funds to libraries, parks and recreation, trash collection, and street cleaning.

Time Phase IV (July, 1979 to end of August, 1979)

In early July, three years after the first information was announced, the U.S. Geological Survey refined the earthquake prediction further. The quake would occur sometime during the first week of september, about 60 days away. The estimated magnitude was 7.3 on the Richter scale, and the probability was still $80 \%$.

1. All efforts to prepare for the earthquake were speeded up. Local government officials urged evacuation of high-risk areas, particularly of areas below some reservoirs. Officials said that police and fire protection for empty houses and buildings would be stepped up, although total protection could not be guaranteed.

2. A Presidential Emergency Declaration for the area was finally announced in August, and officials and businesses hurried to get funds forthcoming from the declaration. The funds were used to further prepare for the possible emergency and to lessen some pressing economic problems in the area.

3. Shelters were established by the Red Cross and other agencies to handle residents who evacuated before the 
possible earthquake.

4. By August, property values had dropped to their lowest point in the last three years, and even lower in areas of expected high damage.

5. General unemployment had risen markedly; unemployment in the construction industry had been high for a long time.

6. Some supermarkets and other retail stores announced they would stay open during the week of the predicted impact.

7. At the direction of the Governor, the National Guard was sent into the area to assist local authorities.

8. Hospitals and prisons transferred their charges to safer locations.

9. Some overpasses and bridges were closed and detours through safer areas were established.

10. As the outflow of population accelerated during the last two weeks, many businesses closed down entirely and the buildings were vacated.

11. One week in advance of the earthquake week, all public buildings were vacated. Records had already been given special protection or relocated. For the few critical governmental functions that continued, skeleton crews operated out of trailer-type offices located well away from buildings and power lines.

In this brief overview of responses it can be seen that some rather significart actions are taken by both governmental and business organisations, with the most intense activity occurring following the raising of the estimated probability to $80 \%$. In Figure 2 we try to depict a few of the major types of actions and to show selected consequences for other organisations and actions.

The earthquake prediction may come from either a governmental agency and/or a public or private university source. Thereafter the two most consequential actions flow from certain government agencies following established policy. First, the state. Insurance Commissioner acts to protect the solvency of insurance carriers operating in his state. He assumes that there will be a run on earthquake insurance and that if the earthquake occurs approximately as predicted, at least some of the companies would become insolvent. That development, he decides, would not be in the public interest. Those persons who had paid premiums for earthquake insurance over the years are entitled to continuing protection and payment for losses if the earthquake comes, he believes. Basically, this is not a new policy but simply the application of previous policy to a new set of circumstances.

The second major triggering action is the appearance in the local newspaper of maps which purport to show where the heavy damage, moderate damage and light damage will occur. Why would any governmental agency want to do that? Several agencies have indicated that their domain includes monitoring and taking action to protect the health and safety of the populace. They interpret that broad responsibility to include the informing of the public of dangerous areas and structures. Thus, they will develop and publicize the damage estimate maps so that the public can be aware of the nature and extent of the danger. Again, basic, traditional policy is reinterpreted to apply to new circumstances in the agency's environment.

But while there are no real surprises in the actions of these governmental agencies, the consequences of those actions for other organisations and the community as a whole are certainly not modest in scope and intensity. The consequences over a two- to three-year period will apparently spell an economic disaster of considerable proportions. At the same time there will be a marked reduction in risk of death and injury. As is so often the case, economic values are at odds with other human values in this setting.

\section{IMPACT OF EARTHQUAKE PREDICTION ON OTHER ADJUSTMENTS TO EARTHQUAKES}

The actions outlined above are responses to a specific earthquake prediction. By and large they are not actions which would be likely to occur as part of the normal adjustment to the generalized earthquake threat. Recall the six traditional types of adjustments a community may make to the earthquake hazard. Of the six, only insurance is altered by the earthquake prediction in a direct and obvious way. The sale of earthquake insurance is halted. Actually, the difference in use of that adjustment is slight. There are normally few earthquake insurance policies in effect anyway. The prohibition on the sale of new policies following the prediction, while it cuts short the sudden new demand, does not significantly alter the use of insurance as a way of coping with potential loss from an earthquake. It does, however, curtail the potential use of earthquake insurance as an adjustment.

Now let us review the other adjustments to the earthquake hazard which a city may be using to note the extent to which the presence of an earthquake prediction produced any alteration.

1. Land use control.

There is unlikely to be any change in this adjustment. When construction slows to a halt most land use considerations fade from existence. Possible exceptions would be where there was concern that the predicted earthquake might trigger landslides or slumping in which case certain threatened parcels of land might be rezoned at least temporarily for less intensive use.

New zoning regulations and stepped-up enforcement seem unlikely under these circumstances. Attention is drawn to other matters.

\section{Seismic resistant construction.}

Following the earthquake prediction there are unlikely to be new construction starts. Buildings and other structures still under construction are likely to be completed simply because a completed structure is less vulnerable to shaking. With new construction at a virtual standstill there will be no pressure to revise the building code. 
Enforcement of the building code may very well be stepped up. Inspectors and their supervisors would know that any errors or oversights in code enforcement on their part could be highly visible after the quake.

Architectural and engineering firms may increase their liability insurance. Work that they are doing outside of the target area is likely to be carried out with greater attention being paid to seismic resistance.

\section{Prevention of secondary impacts.}

Here we would expect the earthquake prediction to produce significant change. Enforcement of fire regulations will increase. Detailed inspection of the storage and use of hazardous materials would occur. Commercial and industrial establishments would be forced to take extra precautions, often at considerable expense, to satisfy demands that their inventory and operations be handled in such a way as to pose no threat to the public safety and that of employees should the earthquake occur earlier than predicted.

It is likely that there would be a safety campaign aimed at homeowners. Emphasis would be on reducing fire hazard by taking certain precautions such as bolting the water heater to the wall to prevent toppling.

\section{Preparedness for emergency response.}

Perhaps the greatest change of all will occur with respect to this adjustment. To the extent that the earthquake prediction is believed valid there will be extensive efforts made to insure a rapid and effective response to the earthquake itself. This will range all the way from installing valves that shut off fuel and water lines automatically when the shaking starts, to standby search and rescue teams, to extra fire fighting forces on the periphery, to having emergency shelter for the homeless ready to operate even before the expected coming of the earthquake. Indeed a case could be made that if earthquake predictions were $100 \%$ accurate there would be no need for a community to develop an emergency response plan specifically for the earthquake hazard until the prediction had been released. A lot of unnecessary planning and cost could be avoided.

\section{Relief and rehabilitation efforts.}

Here, too, the prediction would provide a massive stimulus to action. Local officials and citizens will find out in advance just what Federal and state aid would be available after impact. Plans for the entire disaster assistance operation could be fine-tuned in advance. Space, equipment and personnel could be arranged for. Perhaps most important of all would be the opportunity to plan thoughtfully in advance for the reconstruction of the city. Contingency plans for long range financing of such an effort could be developed (Haas, Kates and Bowden (5),

Let us summarize. An earthquake prediction will have little impact on the normal way in which land use controls and seismic resistant construction are used by a city to mitigate the earthquake hazard. It will cause some increase in actions designed to prevent secondary impacts. The earthquake prediction will be the dominant driving force in increasing by far the scope and intensity of efforts related to preparedness for emergency response and planning for relief, restoration and reconstruction.

In no case does the earthquake prediction produce a diminished application of any adjustment mechanism with the possible exception of insurance, an adjustment which is seldom used anyway.

A credible earthquake prediction serves as a catalyst in the entire adjustment process for the community, as we have seen. But quite apart from that relationship an earthquake prediction has direct effects of its own, negative as well as positive, on the community. Because a prediction contains specific information regarding time, location and magnitude, a host of specific actions can be taken that otherwise would make no sense. Most of those actions deal with the reduction of deaths and injuries. Highly accurate earthquake prediction permits the human habitation of a seismically active area with relative impunity insofar as casualties and emotional trauma are concerned. In addition, earthquake prediction makes possible the avoidance of loss of highly valued objects such as records, art works and certain kinds of equipment. Many such objects simply cannot be replaced. With earthquake prediction they may be used and enjoyed with impunity until the coming of the earthquake.

But all knowledge also has its cost as outlined in Figure 2. The severe local economic depression produced by the earthquake prediction may represent economic loss as great as that produced by the earthquake itself. There are steps that could be taken to soften the negative economic impact of the prediction but it is not clear yet whether those steps will be taken.

\section{CONCLUDING OBSERVATIONS}

What actions, if any, might be appropriate prior to the release of the first prediction for a damaging earthquake?

1. Some measures designed to stabilize property values after the earthquake prediction should be given priority consideration. Most frequently mentioned is some form of Federally subsidized earthquake insurance, perhaps modeled after the current National Flood Insurance Program.

2. Clarification of the legal liability of predictors, public officials and property owners (National Academy of Science).

A. To what extent is the seismologist or his employer liable for the consequences of a prediction if "normal professional standards" are used in developing and releasing the prediction?

B. To what extent are public officials liable if they take only limited action. 
e.g., ordering evacuation only of very clearly unsafe buildings, in the face of an earthquake prediction? Does the degree of liability change as the estimated probability goes up from say $25 \%$ to $60 \%$ ? What liability is inherent in taking more drastic action?

C. Does the employer or property owner face increased liability as a result of an earthquake prediction? If he fails to vacate his property well in advance of the expected earthquake can he be sued successfully for damages and wrongful death?

3. How can drastically increased mitigation and preparedness measures be financed by local government? With tax revenues dwindling and legitimate' demands for budget increases expanding, local government will be in severe financial straights. Should special state and Federal "predisaster" financial assistance be made available? Under what circumstances? Should the aid be comparable to the postdisaster financial assistance normally given?

There are a number of interlinked issues which come into play here.' All of them need immediate attention.

4. Should residents of the "target" community be encouraged to leave the area? How about leaving areas designated as "higher risk" zones?

Especially for the first few predictions there may be a concern that the earthquake may come earlier or be larger than predicted. From a strictly economic perspective residents for the most part should be encouraged to stay and many business leaders may well take that stance. From strictly a safety standpoint most persons should be encouraged to leave for safer areas well in advance of the predicted time. Under exceptional circumstances perhaps forced evacuation would be called for.

For each potential target community there ought to be careful examination of the pros and cons and the probable consequences of different courses of action.

5. Should there be some attempt at controlling the tactics of land speculators?

There is considerable concern among knowledgeable officials that some unethical land speculators will use scare tactics akin to "block busting" to drive down property values. Is there a legal, feasible basis for dealing with such activities?

Earthquake prediction is an emerging technology. Its application in the near future is a near certainty. It is becoming clear that a number of "negative" forces will be set in motion by an earthquake prediction with an extended lead time. If we wish to avoid some of these negative consequences it is high time to consider and adopt some strategies to counterbalance the negative trends. It is also necessary to consider with care how best to utilize the opportunities provided by an earthquake prediction.

\section{ACKNOWLEDGEMENTS}

Many persons have contributed time and helpful ideas to this research effort. They are too numerous to mention here but among those deserving a special note of appreciation are: Heidi Burgess, Harold Cochrane, Thomas E. Drabek, Kenneth Gosting, Janice R. Hutton, Carl Kisslinger, Jacki Lillard, Julia Mewes, Deanna Nervig, Madalyn Parsons, Craig Piernot, Roger Pulley, John Sorensen, Gilbert F. White and Alan J. Wyner.

\section{REFERENCES}

(1) Ayre, Robert S., et al. (1975a), "Earthquake and Tsunami Hazards in the United States: A Research Assessment." Monograph \#005, Institute of Behavioral Science University of Colorado.

(2) Ayre, Robert S. (1975b), "Technological Adjustments to Natural Hazards". \#NSF-RA-E-75-020, National Technical Information Service.

(3) Baker, Earl J. and McPhee, GordonFeldman (1975), "Land Use Management and Regulation in Hazardous Areas: A Research Assessment." Monograph \#008, Institute of Behavioral Science University of Colorado.

(4) Haas, J. Eugene and Drabek, Thomas E., (1973), "Complex Organisations: A Sociological Perspective", The Macmillan Company.

(5) Haas, J. Eugene, Kates, Robert W. and Bowden, Martyn J. (forthcoming), "Reconstruction Following Disaster", MIT Press.

(6) Mileti, Dennis S. (1975), "Disaster Relief and Rehabilitation in the United States: A Research Assessment". \#NSF-RA-E-75-009, National Technical Information Service.

(7) Mileti, Dennis S., Drabek, Thomas E. and Haas, J. Eugene (1975), "Human Systems in Extreme Environments: A Sociological Perspective". Monograph \#021, Institute of Behavioral Science University of Colorado.

(8) National Academy of Sciences (1975), "Earthquake Prediction and Public policy". Printing and Publishing Office, National Academy of Sciences.

(9) White, Gilbert F. and Haas, J. Eugene (1975), "Assessment of Research on Natural Hazards". MIT Press. 
FIGURE 1

TYPOLOGICAL MATRIX OF ORGANISATIONAL RESPONSES TO AN EARTHQUAKE PREDICTION

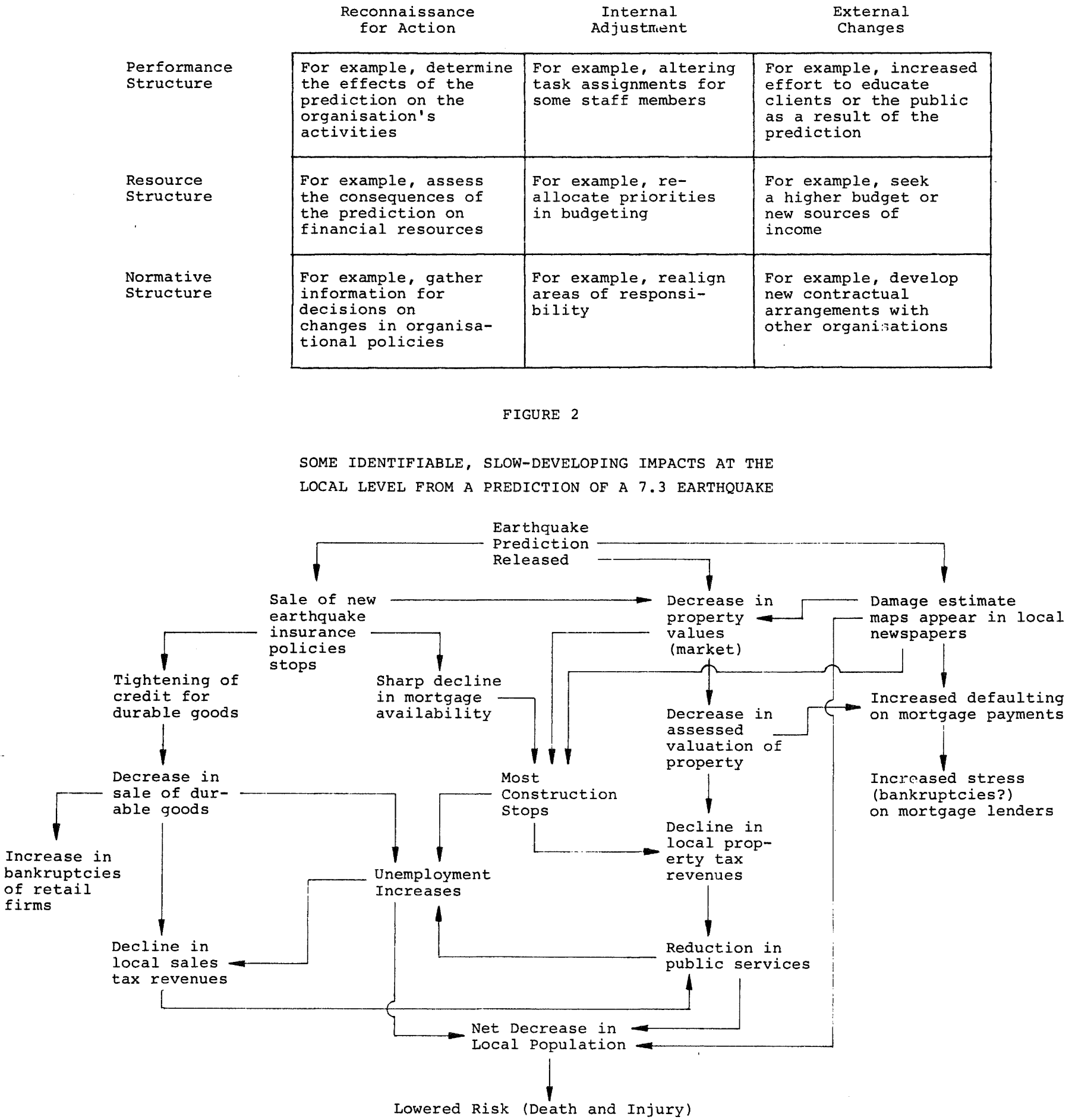

